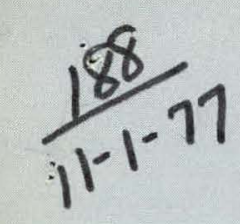

\title{
SAMPLE PREPARATIONS FOR SPARK SOURCE MASS SPECTROGRAPHY
}
C. W. Catlett
M. B. Rollins
E. B. Griffin
J. G. Dorsey 


\section{DISCLAIMER}

This report was prepared as an account of work sponsored by an agency of the United States Government. Neither the United States Government nor any agency Thereof, nor any of their employees, makes any warranty, express or implied, or assumes any legal liability or responsibility for the accuracy, completeness, or usefulness of any information, apparatus, product, or process disclosed, or represents that its use would not infringe privately owned rights. Reference herein to any specific commercial product, process, or service by trade name, trademark, manufacturer, or otherwise does not necessarily constitute or imply its endorsement, recommendation, or favoring by the United States Government or any agency thereof. The views and opinions of authors expressed herein do not necessarily state or reflect those of the United States Government or any agency thereof. 


\section{DISCLAIMER}

Portions of this document may be illegible in electronic image products. Images are produced from the best available original document. 
Reference to a company or product name does not imply approval or recommendation of the product by Union Carbide Corporation or the U.S. Energy Research and Development Administration to the exclusion of others that may meet specifications.

Printed in the United States of America. Available from National Technical Information Service

U.S. Department of Commerce

5285 Port Royal Road, Springfield, Virginia 22161

Price: Printed Copy $\$ 3.50$; Microfiche $\$ 3.00$

This report was prepared as an account of work sponsored by the United States Government. Neither the United States nor the Energy Research and Development Administration, nor any of their employees, nor any of their contractors, subcontractors, or their employees, makes any warranty, express or implied, or assumes any legal liability or responsibility for the accuracy, completeness or usefulness of any information, apparatus, product or process disclosed, or represents that its use would not infringe privately owned rights. 
Distribution Category: UC-4

\title{
SAMPLE PREPARATIONS FOR SPARK SOURCE MASS SPECTROGRAPHY
}

\author{
C. W. Catlett \\ M. B. Rollins \\ E. B. Griffin \\ J. G. Dorsey
}

Plant Laboratory Department

Y-12 Product Certification Division

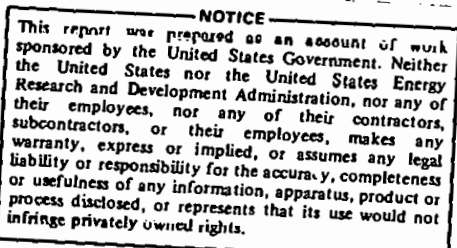

Oak Ridge Y-12 Plant

P. O. Box Y, Oak Ridge, Tennessee 37830

Prepared for the US Energy Research and Development Administration

Under US Government Contract W-7405-eng-26 


\section{ABSTRACT}

Methods have been developed for the preparation of various materials for spark source mass spectrography. The essential features of these preparations (all which can provide adequate precision in a cost-effective manner) consist in obtaining spark-stable electrode sample pieces, a common matrix, a reduction of anomolous effects in the spark, the incorporation of a suitable internal standard for plate response normalization, and a reduction in time. 


\section{CONTENTS}

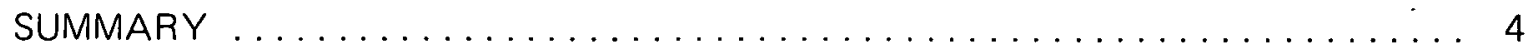

INTRODUCTION $\ldots \ldots \ldots \ldots \ldots \ldots \ldots \ldots \ldots \ldots \ldots \ldots \ldots \ldots \ldots \ldots$

SAMPLE PREPARATION FOR SPARK SOURCE MASS SPECTROGRAPHY $\ldots \ldots \ldots 6$

Experimental Procedure . . . . . . . . . . . . . . . . . . . . . . . 6

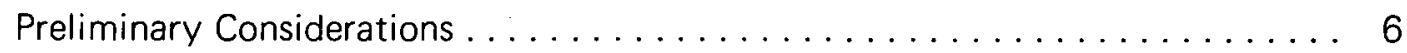

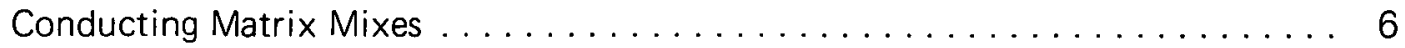

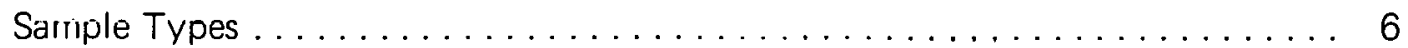

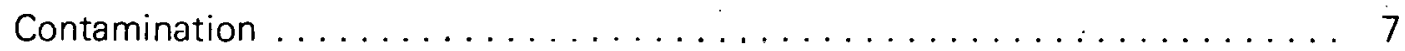

Preparation Procedure $\ldots \ldots \ldots \ldots \ldots \ldots \ldots \ldots \ldots \ldots \ldots \ldots \ldots$

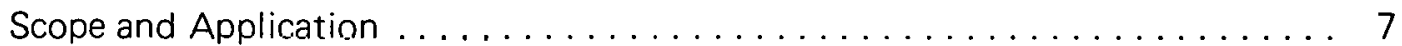

Reagents . . . . . . . . . . . . . . . . . . . . . . . . . . 7

Equipment $\ldots \ldots \ldots \ldots \ldots \ldots \ldots \ldots \ldots \ldots \ldots \ldots \ldots \ldots$

ACKNOWLEDGEMENTS $\ldots \ldots \ldots \ldots \ldots \ldots \ldots \ldots \ldots \ldots \ldots \ldots \ldots$ 


\section{SUMMARY}

This work makes possible a preparation technology which is simple and effective. It seeks to avoid problems common to this kind of mass spectral analysis, such as interference and gas evolution from the specimens, and to provide the phenomena in the ion-generating process that are necessary for adequate quantification of results. The types of samples encountered in this laboratory are many; and, to be more systematic, they have been divided into classes. It was assumed that all laboratories have at their disposal facilities for forming specimen electrodes; but, of course, production of uncontaminated electrodes can be achieved in many ways and with many different types of equipment. There is the problem of homogeneity, and methods have been developed which will assure uniform distributions. It was realized early in the study that much of the property and character of the spark is prompted by the shape and composition of the sample electrodes. For that reason, correct configuration and matrix are essential, and considerable effort was devoted to obtain them.

Since the visual-estimation technique is used extensively in quality assurance of many Plant products, there is no readily available approach to a rigorous evaluation of the improvement in precision. Past experience has shown that better readability of photoplates and a better relation between elemental-ion-beam density and plate blackening result from proper and careful preparation. 


\section{INTRODUCTION}

In analyzing the variety of samples received for spark source mass spectroscopy, it becomes necessary to circumvent as many problems as possible which can occur in the generation of mass spectra from which the desired analytical information is taken. In all instances, samples must be made conductive and put in a form which can be positioned in the electrode holders for ion generation by the spark. It would be disconcerting, for example, if an organic caused high source chamber pressures when subjected to the arc or spark process by evolving large quantities of gas. Similarly, since porous-cup techniques are not currently available, the analysis of a liquid or a solution poses a special problem. The two-fold purpose of this work, conducted at the Oak Ridge Y-12 Plant, (a) can be stated explicitly as: (1) to provide a specimen with a known matrix which reduces anomolous effects, and (2) to skillfully incorporate in the electrode an element of known concentration which can serve as a reliable internal standard. These features are necessary to achieve any semblance of a quantitative analysis of a sample.

(a) Operated by the Union Carbide Corporation's Nuclear Division for the US Energy Research and Development Administration. 


\section{SAMPLE PREPARATION FOR SPARK SOURCE MASS SPECTROGRAPHY}

\section{EXPERIMENTAL PROCEDURE}

\section{Preliminary Considerations}

In spark source mass spectrography, the matrix element must often be supplied for at least three reasons, viz: for electrical conductivity, to have a sample in a sparkable form, and to reduce bulk. This opportunity can be advantageous for controlling the fundamental processes in the spark source, namely ionization and/or vaporization of the sample equiponderantly. To some extent, a proper choice is helpful in obtaining a favorable predisposition for this achievement. For example, a refractory sample without detection requirements that are too stringent may be incorporated with as much as $80-90 \%$ silver powder, which means that to a very marked degree the ionization potential of the ion-generating system will be related to the ionization potential of silver $(7.6 \mathrm{eV})$. A consideration of the spark-discharge phenomenon makes possible a general explanation of the wide variation in the popularly used, but ill-defined, "ionization efficiency" so prevalent in the use of spark sources. At once, it is seen that many factors are present in the ion-generating spark. First, when the discharge occurs, a path for current flow is available which, in effect, short circuits the spark power supply, and the voltage drops rapidly to near zero. During this time, the current increases to several hundred amperes $(600-800)$. In this, the initial part of the oscillatory cycle, it is found that a very strong ionizing voltage 130,000 volts in many sources) decays very rapidly to give rise to highly thermal situations. Secondly, it must be kept in mind that spark sources in mass spectroscopy are mostly small devices that generate relatively small amounts of total power and, thus, there is the need to consider broad distributions and gradients in both ionization and thermal power. Also, it must be borne in mind that neutral atoms are prevalent in spark sources arising from vaporizations and recombinations, or both.

\section{Conducting Matrix Mixes}

Studies of conducting materials which serve as good matrixes indicate that powdered silver, bismuth metal, and graphite are, at the present time, the best. These can be obtained easily, are of very high purity, and are good conductors. There are, of course, such disadvantages as: moisture pickup by the metals, the fragility of the graphite, and some possible line interference. Nevertheless, these three elements allow for duplication of spark behavior from analysis to analysis.

\section{Sample Types}

The kinds of samples that are normally received for analysis can be roughly divided into the following groups: (1) organics, (2) refractories, (3) metals, (4) inorganic compounds, and (5) inorganic solutions and liquids.

Among the organic samples are found high-molecular-weight organic acids, fuels, oils, organic tapes, cleaning agents, polyesters, resins, and hardeners for epoxies. Refractories 
consist of that group of oxides commonly identified by that class name (viz, $\mathrm{BeO}, \mathrm{MgO}$, $\mathrm{SiO}_{2}, \mathrm{Al}_{2} \mathrm{O}_{3}$ ) and also carbides and nitrides. The metals group is comprised of a relatively large group of common metals and alloys, stainless steels, uranium and uranium alloys, and other heavy metal alloys. Some of the metals such as lead, thorium, and beryllium, are toxic in varying degrees and all require special treatment.

Among the inorganic compounds are the usual salts, such as the sulfates, halides, certain sulfides, acetates, and fluorides. As mentioned earlier, all oxides have been classified as "refractories" because of the singular nature of their behavior in the spark. Inorganic solutions and liquids are more accurately identified as electroplating solutions, supernatant liquids from various Plant processes, effluents, water from a variety of sources, mineral acids, and washes from processing in the Planit production facility.

\section{Contamination}

Contamination in virtually all preparations for analytical procedure is a very serious problem, and often the most careful preparation can suffer from gross contamination. A simple rule to follow in minimizing contamination is to allow no surfaces, media, or materials to interface when there is a possibility of the transfer of unwanted material. For example, if a sample is located in a nickel container, and nickel is one of the elements to be identified, the whole purpose of preparation is defeated. Since those interested in this report are usually well aware of the pitfalls of contamination, it is not considered necessary to discuss it thoroughly at this point; but, rather, to describe some special experience in the more detailed preparation technique.

\section{PREPARATION PROCEDURE}

\section{Scope and Application}

These preparations apply to all spark source mass spectrographic procedures in laboratories with many varied missions. While residual levels have a marked influence on preparation, all elemental concentrations are within the scope of these techniques.

\section{Reagents}

Principal reagents that are used in spark source mass spectrography are:

Acetone; ACS specifications.

Acid, hydrochloric $(\mathrm{HCl})$, concentrated; TransistAR grade.

Acid, nitric $\left(\mathrm{HNO}_{3}\right)$, concentrated; electronic grade.

Acid, sulfuric $\left(\mathrm{H}_{2} \mathrm{SO}_{4}\right)$, concentrated; TransistAR grade.

Ammonium hydroxide $\left(\mathrm{NH}_{4} \mathrm{OH}\right)$, concentrated; ACS specifications.

Argon, filtered, high purity; cylinder gas. 
Bismuth metal, powdered, < 100 mesh; $99.999 \%$ pure.

Erbium-170, high purity, solution; $200 \mu \mathrm{g} / \mathrm{cm}^{3}$.

Silver metal, powdered, 200 mesh or less; $99.999 \%$ pure (other enriched isotopes may be used if available).

Water; demineralized.

\section{Equipment}

Principal items of equipment that are needed in this work are:

Balance, analytical, 250-g capacity; any acceptable commercial type.

Balls, mixing.

Block, graphite; with cavities to hold electrodes.

Clean box, plastic.

Crucibles, porcelain; $35-\mathrm{cm}^{3}$ capacity.

Die, tool steel; Riik or its equivalent.

Mixer; Wig-L-Bug or its equivalent.

Mortar and pestle, boron carbide.

Pans, balance, tantalum sheet; $V$ shape.

Plug, compression, polyethylene; $1 / 8^{\prime \prime} \times 1 / 2^{\prime \prime}$ cavities.

Press, nominal 25 ton; Riik or its equivalent.

Tape, plastic.

Tape, Teflon; $1 / 2$ " width.

Vials, plastic; $1 / 2^{\prime \prime}$ diameter by $11 / 2^{\prime \prime}$ long.

\section{Preparation of Samples}

Following are the proposed procedures for sample preparation:

\section{Organic Materials - Liquids -}

1. Pipette milliliters of sample into a clean, glass, open container. Add to this sample a spike of $200 \mathrm{mg}$ of erbium-170.

2. After mixing the spike and sample thoroughly, add one drop of mixed material to the tip of a $1 / 8$-inch-diameter by 1 -inch-long graphite rod. (The end has been previously machined to form a $1 / 16$-inch-diameter by $1 / 4$-inch-long post.) 
3. Dry the drop of material placed on the post and observe the quantity of residue on the post. (Obviously, too much material can lead to difficulty; and, hence, it may be necessary to add only one or just a few drops.)

4. Place the electrodes (in the graphite block) in a muffle and heat them at $300^{\circ} \mathrm{C}$ for 15 minutes.

The electrodes are now ready to be placed in the instrument for the analysis. Two are prepared in this manner for each sample. Caution: great care must be taken to prevent contact of the electrode tip (post) with any material or surface.

\section{Organic Materials - Solids}

1. Weigh a dry sample of from 0.1 to 0.3 gram (depending on the impurity levels) into a 1/2-inch-diameter by 1 1/2-inch-long plastic vial.

2. Add an equal amount of silver powder, which has been spiked with erbium-170 to a precise level of 20 to $30 \mu \mathrm{g} / \mathrm{g}$, and a mixing ball.

3. Mix the sample in the mixer mill for five minutes and then empty it into a $35-\mathrm{cm}^{3}$ crucible. Place the crucible in a muffle and heat the furnace for three hours (in an argon atmosphere) at $400^{\circ} \mathrm{C}$. (Start the heating at room temperature.)

4. Empty a small amount of the mix onto the $V$-shaped balance pan and, without touching the sample material with the hand, transfer the material to the clean compression cavities of the polyethylene press plug (see Figure 1). Tamp the mix with tantalum rods, which can also be used to facilitate the transfer. Repeat until both cavities are filled and tamped.

5. Cut a 3/4-inch-long piece of Teflon tape and cover the cavity openings.

6. Carefully load the plug into the die (see Figure 2) and place it in the press.

7. Apply 25 tons of pressure on the die and hold the pressure for five seconds.

8. Release the pressure and force the plug from the die.

9. Extract the electrode from the plug by removing the tape and rapping the plug against the lip of a clcan plastic vial, allowing the elestrnde to drop into the vial.

10. Cap the vial. The sample electrode is now ready for the analysis.

Ostensibly, each worker has a number of options in technique which can be exercised. It is realized that other approaches may be equally good or even better. This work furnishes only suggestions and guidelines. 

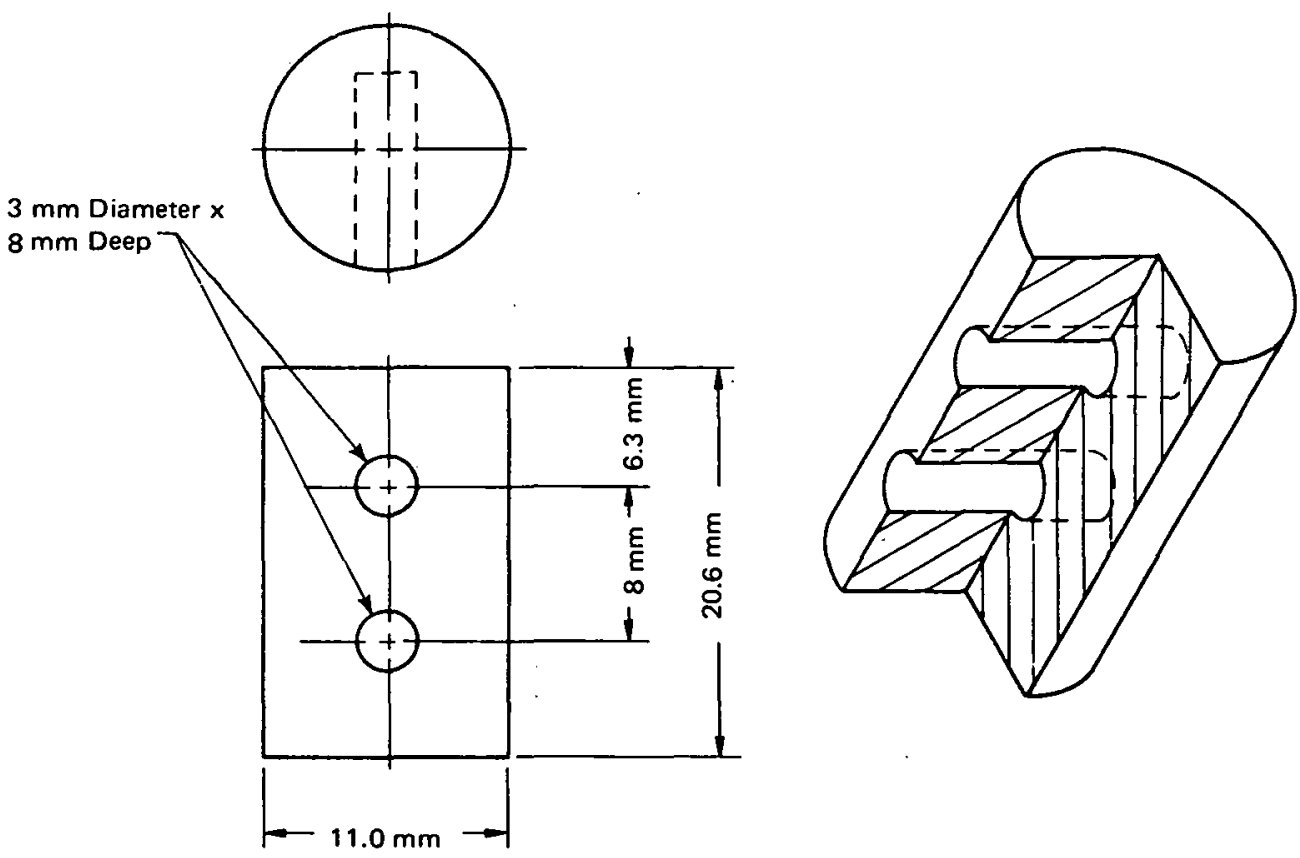

Figure 1. DIMENSIONS OF THE POLYETHYLENE PLUG MOLD.

Refractories - Some materials that have been placed in this group are conductive and compact well-some require a "binder". The first can be pressed into electrodes after particle-size reduction and homogenizing; the second type may require a large portion of silver powder (80-90\%). In any case, there should be a predominant material (ie, a chosen matrix).

Materials which conduct and compact well can be readily formed into electrodes and need unly to be sized and thoroughly mixed to provide a homogeneous state. Certain samples must be made conductive by mixing with silver, carbon, or bismuth, with one material predominant in the mix. For lumpy samples and\%or nonconductive materials, the following procedure has been found to be satisfactory: Place 1.0 to $3.0 \mathrm{~g}$ of the sarnple in a $50-\mathrm{mm}$ boron carbide mortar and carefully grind the sample to $>100$ mesh. Do not grind more than necessary since this precaution will reduce the likelihood of contamination from the grinding process. Proceed as in the preceding section on Organic Materials - Solids.

Splinter and thread-like refractory materials are treated as follows:

1. Place a small weighed quantity $(1$ to $2 \mathrm{mg})$ of the material in each cavity in the polyethylene plug.

2. With the tamp, press the sample to the bottom of the cavity.

3. Add silver powder to the cavity until filled, and tamp. Repeat this step until the cavity is full.

4. Press, as described previously (Page 9; Steps 6-8). 


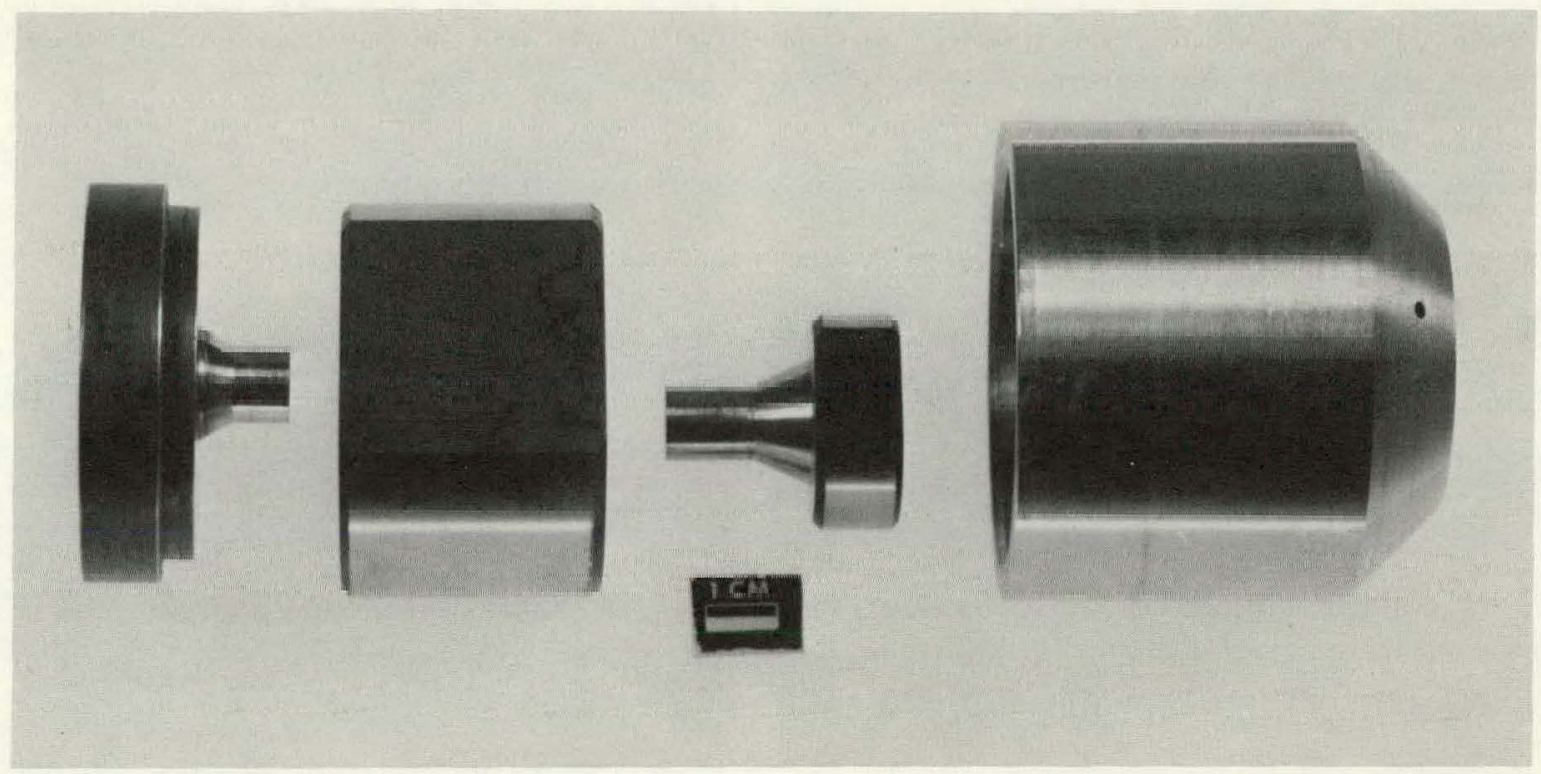

(a) Side View.

173134

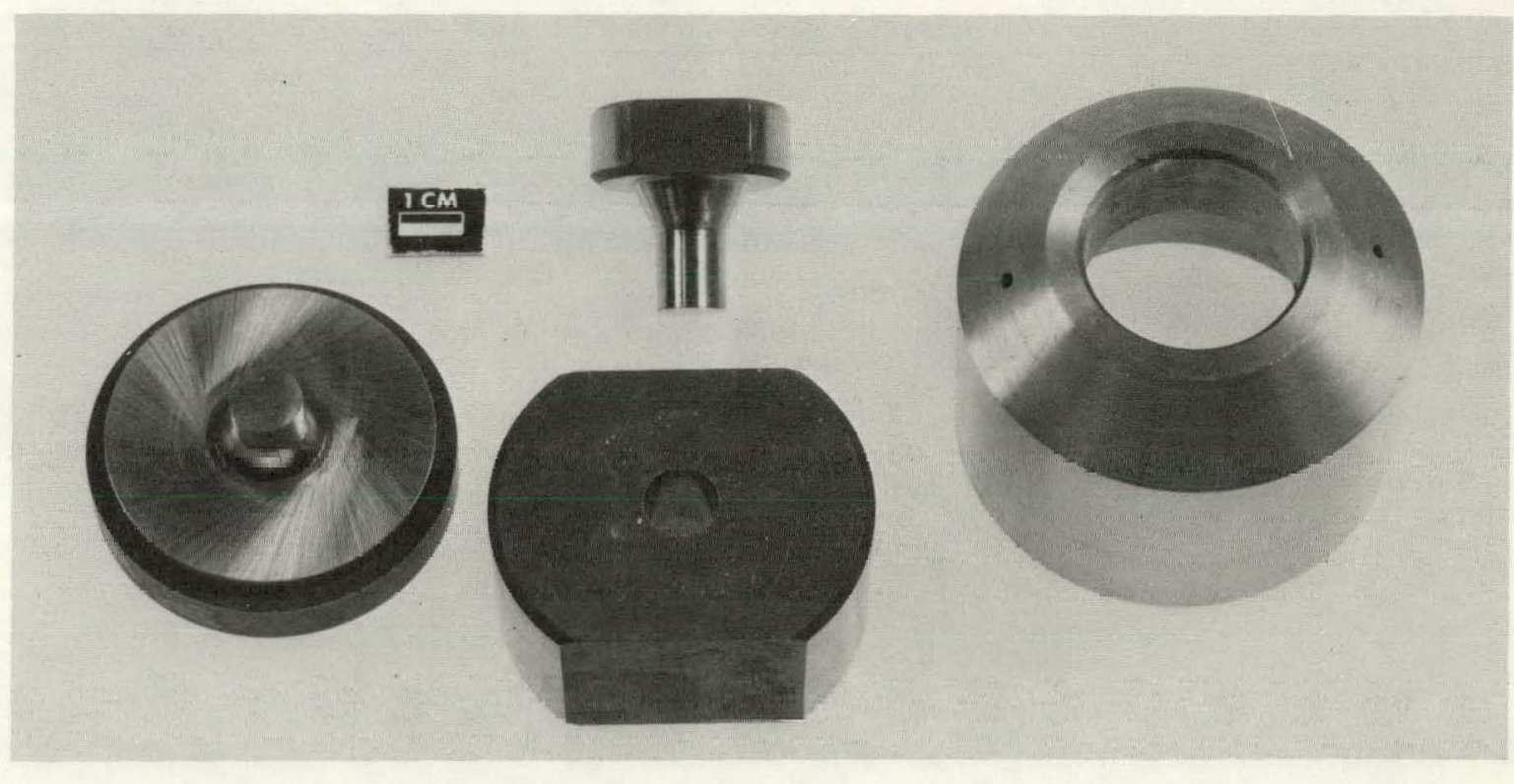

(b) Top View.

173135

Figure 2. PRESSING-DIE COMPONENTS.

The electrodes that are obtained have the sample imbedded in or near the conductive electrode tip and can be sparked in essentially the same way as any silver electrode.

Metals - Metals are received as powders, machine turnings, chunks, and rods. Most powdered metals up to 60 mesh can be compacted by the press into electrodes. Chunks and rods can be cut to size with machine tools or a saw to form the proper electrodes needed for the analysis. Machine turnings can be broken into electrode-size pieces and sparked. Metal chips 
larger than 60 mesh, or types that cannot be compacted well, are tipped on a silver electrode as described under Refractories or pressed in a Ringsdorff die to form a rod.

Metals must be cleaned thoroughly according to the following procedure:

1. Wash the metal three times in acetone to remove grease or oil.

2. Clean the metal surfaces with acid. (Choose the kind and concentration of acid which will prevent the leaching of impurities and yet clean the surface.) Clean with three different portions of acid with a water wash between cleanings. Rinse thoroughly.

3. Allow the metal to dry in air. It is now ready for further preparation.

The Ringsdorff die is a special die made of very hard tool steel. Considerable pressure can be exerted on pieces of metal by the plate-shaped plunger when pressed at 10 tons. There is some contamination from the die, but it is surprisingly small.

Solutions - Solutions can be prepared for analysis by two techniques: (1) the material may be dried on a graphite rod, one tip of which is machined into a post; (2) the solution can be pipetted onto pure silver powder, dried, and pressed into electrodes. The solution can be concentrated by boiling, if needed.

The first technique should proceed as follows:

1. Place the graphite electrodes (rods) in a carbon electrode holding block and locate them under infrared lamps to dry for about 15 minutes. (In this laboratory, a hot plate is used in conjunction with the lamps to heat the block during drying.)

2. Add the appropriate internal standards to a known amount of sample. It is suggested that the following enriched isotopes be considered: $\mathrm{Ba}-137, \mathrm{Cd}-106, \mathrm{Er}-170$, Fe - 57, Mg - 25, Mo-97, Pb-204, Rb-87, Sm-149, W-183, and Zn-67. If these isotopes are not readily available, a selection of elements can be made which are not present in the samples and yet meet the mass, melting and boiling point, and ionization potential requirements.

3. Pipette a drop of solution or liquid onto the electrodes. Allow the solution to dry.

4. Add the sample drop by drop, drying after each application. (See section on Organic Materials - Liquids.)

5. When the sample aliquant, or required quantity, has been added to the electrode post, place the electrode block and electrodes in an oven and heat them at $250^{\circ} \mathrm{C}$ for 15 minutes.

6. Analyze the sample according to the procedure.

The second approach proceeds thus:

1. Add a known quantity of solution containing internal standards to a weighed amount of pure (99.999\%) silver powder in a clean crucible. 
2. Dry and heat the sample for 15 minutes at $300^{\circ} \mathrm{C}$ in an oven.

3. Remove; and, after cooling, press the sample into electrodes.

\section{DISCUSSION}

In this report, the assumption is that interest in this work is restricted, mostly, to those in the business of spark source mass spectroscopy. Therefore, only those preparations which are unique have been described. Emphasis has been given to the dangers of contamination, especially in light of the very low levels of detection which are often required in the spark source. Dies used in electrode formation should be made of materials which will not transfer to the sample any foreign matter on the die surface or any of the fabricated material of the die itself. The Ringsdorff die is made of a special steel that can prevent contamination, but these dies must be cleaned with the proper cleaning materials after each use.

Addition of a spike is considered to be a very important part of sample preparation. The difference between the spike and the usual internal standard is generally only a matter of the amount of material added at some point in the scheme of preparation. The spike is also a valuable technique is visual estimation, where an amount is added that is relatively larger than that in the internal-standard approach wherein a microphotometer (Densitometer) is used. The spike material can be added to very pure silver powder and very thoroughly mixed for general use in forming silver-sample electrodes.

A very rough estimate of the impurity levels in the sample can be useful in sample preparation, in that the amount of a solution dried on a graphite electrode tip can be kept to a minimum, or the silver powder may be increased in a mixture to better control or compensate for anomolous effects in the spark.

As long as the electrode matrix is kept the same, factors can be applied to compensate for the anomalies; and, recently, it was found that in at least one material the sensitivity coefficient coverage was so small that one coefficient could be used for all the elements determined.

To illustrate the large differences that can occur in the coverage when a different matrix is considered, recent work by King, Catlett, and Marshall, (b) showed considerable differences in sensitivity coefficients in silver from that seen in graphite, which is understandable. Note that the matrix referred to is the predominant material in the sample electrode, not the sample itself. The electrode properties are of paramount importance since the spark impinges on the final clectrode matcrial.

It has become increasingly obvious that sample preparation is so interwoven with the mass analysis scheme that the two are inseparable. Indeed, sample preparation may well be the most important single factor.

(b) Members of the $\mathrm{Y}-12$ Plant Laboratory. 


\section{ACKNOWLEDGEMENTS}

A special word of appreciation is extended to H. G. King and J. L. Marshall, members of the Plant Laboratory Department, for their help in this study. 


\section{Distribution}

\section{Bendix - Kansas City}

Baker, G. K.

Jackson, L. C.

Larsen, F. N.

Smith, C. H.

Energy Research and Development

Administration - Oak Ridge

Hickman, H. D.

Leed, R. E.

Zachry, D. S., Jr

\section{Lawrence Livermore Laboratory}

Althouse, L. A.

Cady, W. E.

Firstenberg, G.

Hammon, H. G.

Holder, B.

Nelson, W. E.

Seaton, D. L.

\section{Los Alamos Scientific Laboratory}

Casados, E.

DuBoise, F.

Hoyt, H. C.

\section{Monsanto-Mound Laboratory}

Dichiaro, J.

\section{Oak Ridge Gaseous Diffusion Plant}

Carpenter, L. J.

Keyser. R. M.

Levin, R.W.

Stewart, J. H., Jr

Stief, S. S.

Weber, C.W.

Wilcox, W. J., Jr

\section{Oak Ridge Natinnal Laboratory}

Benjamin, B. M.

Brown, L. L.

Carter, J. A.

Franklin, J. C.

Weir, J. R., Jr

\section{Oak Ridge Y-12 Plant}

Bernander, N. K.

Briscoe, O.W.

Burditt, R. B.

Catlett, C. W. (5)

Childress, F. G.

Creech, E. T.

Dodson, W. H.

Dorsey, G. F.

Dorsey, J. G. (5)

Duggan, H. G.

Eager, M. H.

Ebert, T. H.

Fraser, R. J.

Griffin, E. B. (5)

Harman, W. D.

Huddleston, R. L.

Jones, F. W.

Keith, A.

King, H. G.

Kite, H. T.

Marrow. G. B.

Martin, W. R./Googin, J. M.

Mason, D. L./Schreyer, J. M.

McLendon, J. D.

Mills, J. M., Jr

Morrow, R.W.

Peck, C. G.

Phillips, L. R.

Rhew, J. E.

Rollins, M. B. (5)

Rowan, J. H.

Smith R. D.

Smith, W. E.

Stephens, L. A.

Tewes, W. E.

Thomason, J. C.

White, J. C.

Whitehead, H. D.

Y-12 Central Files (6)

Y-12 Central Files(master copy)

$Y$-12 Central Files (route copy)

$Y-12$ Central Files $(Y-12 R C)$

Zava, A. K.

Paducah Gaseous Diffusion Plant

Bewley, H. D.

In addition, this report is distributed in accordance with the category UC-4. Chemistry, as given in the USERDA Standard Distribution Lists for Unclassified Scientific and Technical Reports, TID-4500. 